NOT FOR QUOTATION

WITHOUT PERMISSION

OF THE AUTHOR

RESOURCES AND NORTH-SOUTH TRADE:

A MACRO ANALYSTS IN OPEN ECONOMIES

Graciela Chichilnisky

December 1983

WP-83-123

Working Papers are interim reports on work of the International Institute for Applied Systems Analysis and have received only limited review. Views or opinions expressed berein do not necessarily represent those of the Institute or of its National Member Organizations.

INTERNATIONAL INSTITUTE FOR APPLIED SYSTEMS ANALYSIS 2361 Laxenburg, Austria 


\section{FOREFORD}

This is one of three papers derived from research on North-South resource trade performed in the System and Decision Sciences Area during the summer of 1982. The aim of this research was, first, to construct a model of North-South resource trade and then to use it as a framework for further work in gaming, negotiations, and interactive decision making.

In this paper, Graciela Chichilnisky investigates the impact of resource export policies on the major macro variables of exporting and importing economies, and shows that the effects of increasing resource exports can be either beneficial or harmful, depending on the structure of the economy and the endogenous factor prices.

ANDRZEJ WIERZBICKI

Chairman

System and Decision Sciences 


\section{ABSTRACT}

This paper explores the impact of resource export policies on the major macro variables of exporting and importing economies. Two regions, North and South, trade resources for industrial goods. Each region produces two goods with three factors: capital, labor and resources. The relative prices in the five factor and goods markets, as well as the outputs, consumption and international trade levels, are all determined endogenously. The general equilibrium is parameterized by the volume of resources traded.

An increase in resource exports may be either beneficial or harmful, depending on the characteristics of the trading economies. When the South's economy is dual, the North's homogeneous, and the rates of profit are high, increases in resource exports are associated with lower real wages, employment and consumption in the South; the South's terms of trade and its export revenues decrease. This is traced to changes in the domestic terms of trade between the traditional and the industrial sectors. However, the profits in the South increase, thus explaining in part the expansion of exports under these circumstances.

More favorable outcomes are obtained by increasing resource exports when the exporting economy is more homogeneous. Sufficient conditions are given for an export policy that increases the welfare of the exporting country, improves its international terms of trade and increases its export revenues.

The characteristics which determine whether an expansion of resource exports is beneficial or harmful to the economy are the structure of the economy and the endogenous factor prices. Since the equilibria and the associated values of endogenous variables are determined for a given level of resource exports, it follows that whether it is better to increase or decrease the volume of resources exported will depend on the equilibrium level of exports. It is therefore possible to determine the optimal level of exports for an economy of a given structure. 


\title{
RESOURCES AND NORTH-SOUTH TRADE: \\ A MACRO ANALYSIS IN OPEN ECONOMIES
}

\author{
Graciela Chichilnisky*
}

\section{INTRODUCTTON}

This paper explores the impacts of resource export policies on the major macro variables of exporting and importing economies. These impacts are traced back to changes in international terms of trade and in total revenues. The paper thus belongs to the emerging literature on macro analysis of open economies (e.g., Benavie, 1978; Bliss, 1981; Corden, 1982) as well as to the more recent body of work concerned with general equilibrium analysis of resource export policies (Chichilnisky, 1981, 1983; Cremer and Salehi, 1980; Dasgupta and Heal, 1979).

The North-South model proposed here is an extension of that given in Chichilnisky (1981) to an economy with two goods and three factors of production, one of which is traded internationally. The aim is to explore certain

\footnotetext{
- Professor of Economics, Columbia University. This research was supported by NSF grant No. SES 7914050 and a Rockefeller Foundation International Relations Award. I thank P. Dasgupta, G. Heal, D. Horwell and A. Wierzbicki for helpful comments. (This is a revised version of an Essex Economic Paper first circulated in 1981.)
} 
issues in Nortb-South trade. The two trading regions (North and South) therefore have the macro characteristics of industrial and developing countries, respectively. As in Chichilnisky (1981), the resource-exporting region has a dual structure; its traditional sector uses mostly labor, with very low capital or oil inputs, while its industrial sector is quite capital- and oilintensive. The industrial economy has a more homogeneous structure and does not produce resources. For completeness, we also study a case (Theorem 3) in which the resource importer is also a developing country.

We consider here resources which are 'pure rent' goods, and are extracted mostly for export. The resource sector is linked to the domestic economy mainly through the international market: resources are exchanged for industrial goods and these affect all domestic markets.

We focus on certain issues of North-South resource trade which appear to be at odds with the conventional wisdom. With abundant resources, an exporting economy is usually expected to fare well, avoiding balance of payments and foreign exchange constraints, and the usual restrictions on industrial goods.*

However, the experiences of Mexico, Venezuela and Nigeria in recent years suggest that the effects of concentrating on resource exports are more complex. The possible harmful consequences of exporting resources on the domestic economy have also featured in the economic agendas of several industrial countries, such as the UK, Holland and Australia, being variously referred to as a "de-industrialization" phenomenon, the "Dutch disease" and the "Gregory syndrome". For a review of this latter literature on industrial economies, see, e.g., Corden (1982).

- Unless one postulates exogenous, ebsorptive constraints, as in Cremer and Salehi (1980). This is not done here. 
The point developed here is that resource exports may affect the market structure of a developing country in ways that cannot be captured by onesector models, requiring instead a general equilibrium analysis with at least two productive sectors, traditional and industrial, and with variable market prices. The impact of resource exports can then be seen in the changes they induce in relative prices and, in particular, in their effects on the terms of trade between traditional and industrial sectors. These price changes in turn cause important income effects that alter traditional links between international and domestic markets.

The interest of the results lies in their simple, but somewhat unexpected, identification of the problems and solutions. Dual developing economies which trade resources for industrial goods with more homogeneous industrial economies may actually suffer if they increase their exports. Employment and consumption may decrease, and the terms of trade worsen. However, although export revenues decrease, there is an increase in domestic income from profits and an increase in the rate of profit, explaining perhaps why trade takes place at all. The importing economy generally benefits more than the exporter in this case.

In more integrated economies with more homogeneous technologies, increased exports have a positive domestic impact, although the international terms of trade can worsen. The most positive outcomes occur when the exporter trades with a dual economy: real revenues generally increase with exports and the main welfare indicators improve. However, the welfare impacts on the resource importer may be less positive in this latter case. The characteristics which determine whether a.s expansion of resource exports is beneficial or harmful to an economy are the structure of the economy and the endogenous factor prices. Since the equilibria are characterized by the 
volume of resources exported, it follows that whether it is better to increase or decrease resource exports will depend on the equilibrium level of exports. It is therefore possible to determine an optimal level of exports for an economy of a given structure. This provides the optimal balance between domestic use and exports.

The results indicate possible strategies for resource exporters, in that they identify precisely what constitutes an appropriate domestic environment for the export of resources and also determine an appropriate balance between domestic consumption and exports. They also provide a warning about excessive reliance on resource exports as a means of encouraging development.

\section{SPECIFICATION OF THE YACRO YODEL}

The model considers two regions, called the 'North' and the 'South'. Each is represented by a general equilibrium system consistent with a competitive market economy. This model is an extension of that given in Chichilnisky (1981) with some notable differences: it includes three factors of production instead of two, and one of the regions trades a factor (the resource) rather than a commodity.

Each region produces two commodities: a 'basic' consumption good $B$ and a luxury/investment good denoted $I$, which is also called the 'industrial' good. In addition, the South produces a resource, which from now on we shall call oil, denoted $\vartheta$. Goods $B$ and $I$ are consumed; oil is an input of production. The other two inputs are capital $K$ and labor $L$. The North exports industrial goods in exchange for oil from the South. The prices of the two commodities are denoted $p_{B}$ and $p_{7}$, the prices of the three factors are $p_{\vartheta}, r$ and $w$. 
We first outline the model of one region, the South. There are five behavioral equations, which describe production, supply of factors, and demand. The production system is formalized by the equations:

$$
\begin{aligned}
& B^{S}=\min \left(L^{B} / a_{1}, v^{B} / b_{1}, K^{B} / c_{1}\right) \\
& I^{S}=\min \left(L^{I} / a_{2}, v^{I} / b_{2}, K^{I} / c_{2}\right) .
\end{aligned}
$$

where the superscripts $B$ and $I$ indicate the type of good and hence the sector. and the superscript $S$, the supply. There is a constraint on oil supplies, $\vartheta \leq \bar{\vartheta}$

The supplies of labor and capital are price dependent:

$$
\begin{aligned}
& L^{S}=\alpha\left(\frac{w}{p_{B}}\right), \quad \alpha>0 \\
& K^{S}=\beta r, \quad \beta>0,
\end{aligned}
$$

where $w$ denotes wages, $r$ the rate of profit or quasi rent of capital and $\boldsymbol{p}_{B}$ the price of $B . *$

We postulate the following demand behavior at equilibrium:

$$
p_{B} B^{D}=w L
$$

where $L$ is total labor employed and the superscript $D$ denotes demand, i.e., $B$ is a 'wage good'.**

Equations (1)-(5) complete the behavioral assumptions of the model. Our next task is to define the general equilibrium of the North-South model by the solutions to a system of simultaneous equations. To this end, we first

\footnotetext{
- More general supply functions can be used for labor and capital, at the cost of increased complexity. Eramples include general linear functions such as $L^{S}=\left(a w / p_{B}\right)+\bar{L}$ and functions of the form $L^{S}=\left(w / p_{B}\right)^{a}$.

-"Equation (5) is only valid at equilibrium; no disequilibrium demand behavior is specified as we are only concerned here with comparative static analysis across equilibria. Fhile (5) simplifies the computations, it is not crucial to the results: all that is required is that the proportion of wage income spent in the industrial sector is significantly lower than that of profit income.
} 
derive certain relations between factor prices and commodity prices, and between output and employment of factors, which are subsequently used to specify an equilibrium in the simplest possible form.

From the production functions (1) and (2), assuming competitive behavior, we obtain the "dual" price equations relating factor and output prices:

$$
\begin{gathered}
p_{B}=a_{1} w+b_{1} p_{v}+c_{1} r p_{I} \\
p_{I}=a_{2} w+b_{2} p_{\vartheta}+c_{2} r p_{I}
\end{gathered}
$$

where $r p_{I}$ is the "user's cost of capital". In addition, from (1) and (2) we derive a relation between levels of output and employment of factors:

$$
\begin{gathered}
L=L^{B}+L^{I}=a_{1} B^{S}+a_{2} I^{S} \\
K=K^{B}+K^{I}=c_{1} B^{S}+c_{2} I^{S} \\
\vartheta^{D}=b_{1} B^{S}+b_{2} I^{S} .
\end{gathered}
$$

From (8) and (9) we obtain equations for the supply of $B$ and $I$ in terms of labor and capital employed:

$$
\begin{gathered}
B^{S}=\left(c_{2} L-a_{2} K\right) / D \\
I^{S}=\left(a_{1} K-c_{1} L\right) / D .
\end{gathered}
$$

where $D=a_{1} c_{2}-a_{2} c_{1}$.

The next step is to define the equilibrium of the North-South model by the solutions to a system of simultaneous equations. Note that once the equilibrium outputs of commodities $B$ and $I$ are known in one region, the employment of factors (labor, capital and oil) in this region can be determined from equations (8) and (9). 
An equilibrium in the commodity markets $(B, I$ and $\vartheta$ ) of the South can be expressed by a system of four market-clearing equations:

$$
B^{S}=B^{D}
$$

i.e., $B$ is not traded internationally;

$$
I^{S}=I^{D}-X_{I}^{D}
$$

where $X_{I}^{D}$ denotes imports of $I$;

$$
v^{S}=v^{D}+X^{S}
$$

where $X_{v}^{S}$ denotes oil exports; and the balance of payments condition

$$
p_{\vartheta} X_{\vartheta}^{S}=p_{I} X_{I}^{D}
$$

We now consider the two-region model. We postulate the same behavioral equations (1)-(5) for the North, and obtain another set of four equations analogous to (13) $-(16)$, but possibly with different values for parameters $\alpha, \beta$, $a_{1}, a_{2}, b_{1}, b_{2}, c_{1}$ and $c_{2}$. Also, $\vartheta^{S}(\mathrm{~N})=0$ since we assume that the North produces no oil. A world trade equilibrium can now be defined by a system of eight equations: (13)-(16) for the South, and the corresponding four equations for the North. Note that, in a world trade equilibrium, the exports of oil from the South $X_{0}^{S}(\mathrm{~S})$ must equal imports of oil to the North $X_{v}^{D}(\mathrm{~N})$, where the $\mathrm{S}$ and $\mathrm{N}$ in parentheses indicate that the variables refer to the South and the North, respectively. Similarly, $X_{I}^{\dot{D}}(\mathrm{~S})=X_{I}^{S}(\mathrm{~N})$. In addition, in a world equilibrium, the prices of traded commodities are equal across regions, i.e., $\boldsymbol{p}_{\vartheta}(\mathrm{S})$ $=p_{v}(\mathrm{~N})$ and $p_{I}(\mathrm{~S})=p_{I}(\mathrm{~N})$. (The prices of non-traded factors and goods may, of course, differ between regions.) This implies that if the balanced budget condition is met in the North it will also be met in the South, and vice versa. We therefore have a system of seven independent equations defining the world trade equilibrium. 
In order to solve the model, we shall now rewrite these seven equations as functions of specific variables: prices, oil supplies and traded volumes. The equation $B^{S}=B^{D}$ may be rewritten in view of (11), (3). (4) and (5) as:

$$
\frac{\alpha c_{2} w}{D p_{B}}-\frac{\beta r \alpha_{2}}{D}-\alpha\left(\frac{w}{p_{B}}\right)^{2}=0
$$

Next we shall rewrite $I^{S}=I^{D}-X P$. Noting that in equilibrium the national income identity

$$
p_{B} B^{D}+p_{I} I^{D}=w L+p_{v} v+\boldsymbol{r p}_{I} K
$$

is always satisfied, the demand equation (5) implies

$$
p_{l} I^{D}=p_{\vartheta} \vartheta+r p_{I} K
$$

in equilibrium, where $v=0$ in the North. Therefore, from (12). (3). (4) and (19) the expression $I^{S}=I^{D}-X P$ is identical to:

$$
\beta r^{2}+\frac{p_{\theta} \vartheta}{p_{I}}-\frac{\beta a_{1} r}{D}+\frac{a w c_{1}}{D p_{B}}-X_{I}^{D}=0
$$

Similarly, from (10), (11) and (12), the export equation for oil $X^{S}=\vartheta^{S}-\vartheta^{D}$ is

$$
\vartheta^{S}-X_{i}^{S}-\frac{a w}{D p_{B}}\left(b_{1} c_{2}-b_{2} c_{1}\right)-\frac{\beta r}{D}\left(a_{1} b_{2}-a_{2} b_{1}\right)=0
$$

Finally, we have, as before, one balance of payments condition:

$$
p_{\vartheta} X_{t}^{S}=p_{I} X_{I}^{D}
$$

We therefore have seven equilibrium equations: (17). (20). (21) and (22) for the South, and those corresponding to (17). (20) and (21) for the North. Recalling that in a trade equilibrium the prices of traded goods are equal across the two regions, the seven equilibrium equations therefore depend on the following nine variables: $p_{\vartheta} \cdot p_{I}, w / p_{B}(N), w / p_{B}(S), r(N), r(S)$, traded volumes $X_{I}^{D}(\mathrm{~S})\left(=X_{I}^{S}(\mathrm{~N})\right), X_{v}^{S}(\mathrm{~S})\left(=X_{v}^{D}(\mathrm{~N})\right)$ and oil supplied $\vartheta^{S}$. Therefore, as usual with general equilibrium models, we may solve the system in relative 
prices, except for the value of one variable which must be set exogenously. We choose the numeraire to be oil, i.e., $p_{\vartheta}=1$, and the exogenously set variable to be the volume of oil exports, $X_{\vartheta}^{S}(S)$. For each volume of exports $X_{\vartheta}^{S}(S)$, we may therefore compute a (locally unique) equilibrium of the North-South economy, where the prices $p_{I}, r(\mathrm{~S}), r(\mathrm{~N}), w / p_{B}(\mathrm{~S}), w / p_{B}(\mathrm{~N})$ and the volume of industrial goods exported $X_{I}^{S}(\mathrm{~N})$ are all determined endogenously. From these values, we may also compute the equilibrium values of all other variables in the North-South model: using the supply equations (3) and (4) we obtain the employment of factors in each region; using equations (11) and (12), the levels of output of $B$ and $I$; from (5), demand for $B$; and from the price equations (6) and (7), the values of $w$ and $p_{B}$ in each region.

The North/South terms of trade $p_{\vartheta} / p_{I}\left(=1 / p_{I}\right)$ are therefore determined endogenously at each equilibrium, depending on the volume of oil exported. The Appendix shows how these equilibrium positions may be calculated, and that the equilibria form a one-parameter family characterized by the volume of oil exported.

The next section explores the changes in the major macro variables that follow a change in the (exogenously determined) volume of oil exported $X_{v}^{S}(S)$.

\section{GAUGING THE ADVANTAGES OF OIL EXPORT POIJCIES}

Here we explore the macro impact of a move towards a new world trade equilibrium with a higher level of oil exports from the South. As we shall see, certain characteristics of the economies of the two regions bave quite a striking effect on the results of such export policies, i.e., on the volume of industrial goods which are traded for oil, on the real wages, and on the overall consumption and employment of factors in both regions. This allows us to study the possible advantages and disadvantages of different oil export policies, and 
to focus on the parameters that determine the outcomes of such policies.

This section proves the main results analytically; possible policy implications are discussed in the next section. The following assumptions are now made concerning the economies of the two regions:

$D=a_{1} c_{2}-a_{2} c_{1}>0$ in both regions, i.e., the industrial good is more capital-intensive and the basic consumption good more labor-intensive.

A.2 The South's production of basic goods requires a lot of labor and only small amounts of oil and capital, i.e., $b_{1}$ and $c_{1}$ are small in the South.

A.3 E $E=b_{1} a_{2}-b_{2} a_{1}>0$ in the North, i.e., the North's basic good is more oil-intensive and the industrial good more laborintensive. Alternatively we may assume that $b_{1} a_{2}-b_{2} a_{1} \simeq 0$. i.e., they have approximately similar intensities in oil and labor.

A.3 is a natural assumption when, for example, the "non-traded" good $B$ in the North is services or certain manufactures, and good $I$ consumer durables, vehicles, military equipment, etc. It will be shown below that this assumption is not necessary to obtain the results, but it simplifies the computations considerably.

We can now prove the following theorem:

Theorem 1. Assume that the economies of the two regions are as specified in Section 2 , and that the following conditions are satisfied. In the South

C. 1

$$
\frac{c_{2}}{D}<\frac{2 w}{p_{B}}
$$


i.e., the economy is 'dualistic' in its use of capital and labor, so that $D$ is large. In the North

$$
\frac{c_{2}}{D}>\frac{2 w}{p_{B}}
$$

i.e., the sectors are relatively homogeneous. We assume the rates of profit to be relatively high, so that $2 r>a_{1} / D$ in both regions.

In this case a move towards a new world equilibrium with increased oil exports from the South will necessarily worsen the terms of trade of the South and decrease its real revenues. Real wages, total employment and the domestic consumption of basic goods will all decrease in the South.

However, the rate of profit and the total profit income will increase in both regions with increased trade in oil.* In the North, the new equilibrium will lead to more employment, and to increases both in the real wage and in the domestic consumption of basic goods.

Proof. The strategy of the proof is as follows. First we show that, under the stated conditions, an increase in oil imports raises the domestic rate of profit in the North across equilibria. Next we show that, as this rate of profit rises, the volume of industrial goods exported from the North $X_{I}^{S}(\mathrm{~N})$ falls across equilibria, due to income effects. Therefore, in the new equilibrium with increased oil exports from the South, the North will export fewer industrial goods: the terms of trade of the South will worsen, and its real revenues in terms of industrial goods will fall. The rest of the proof traces the impact of the changes in the international market on the domestic economies of the two regions.

-The fact that real wages $w / p_{B}$ and the profit rate $r$ increase in the North does not imply that both factor prices $w$ and $r$ move in the same direction in the North, since real wages are deflated by the price of the good $B, \boldsymbol{w} / \boldsymbol{p}_{B}$, and $B$ is not the numeraire. 
First we establish that the rate of profit in the North increases with the volume of oil exported from the South, i.e.,

$$
\frac{\partial X_{v}^{S}(\mathrm{~S})}{\partial r(\mathrm{~N})}>0
$$

Consider the amount of oil imported by the North $X_{\mathbb{v}}^{D}(\mathrm{~N})$. Since the North produces no oil, $X_{v}^{D}(\mathrm{~N})=\vartheta^{D}(\mathrm{~N})$. In equilibrium, of course, $X_{\vartheta}^{D}(\mathrm{~N})=X_{v}^{S}(\mathrm{~S})$, so that it suffices to find the sign of $\partial X_{v}^{D}(\mathrm{~N}) / \partial r(\mathrm{~N})$. The change in the rate of profit in the North as the South exports more oil can be traced to the changes in prices that must take place in order that the North may utilize more oil.

Since the total volume of oil required by the North is the sum of oil demands in the industrial sector $I$ and in the basic goods sector $B$ :

$$
v^{D}(\mathrm{~N})=X_{v}^{D}(\mathrm{~N})=b_{2} I^{S}(\mathrm{~N})+b_{1} B^{S}(\mathrm{~N})
$$

In order to find the relationship between oil imports and the rate of profit in the North, we now write $I^{S}$ and $B^{S}$ as functions of the total labor and capital employed. Dropping the region identifier $(\mathrm{N})$ where the region is obvious:

$$
\begin{aligned}
X_{v}^{D}(\mathrm{~N}) & =\frac{b_{2}}{D}\left(a_{1} K-c_{1} L\right)+b_{1} B^{D} \\
& =\frac{b_{2}}{D}\left(a_{1} K-c_{1} L\right)+b_{1} \alpha\left(\frac{w}{p_{B}}\right)^{2} .
\end{aligned}
$$

where we have used equations (12), (3) and (5). Since the factors employed depend on their prices $((3)$ and (4)), we obtain

$$
X_{B}^{D}(\mathrm{~N})=\frac{\beta b_{2} a_{1} r}{D}+\alpha\left(b_{1}\left(\frac{w}{p_{B}}\right)^{2}-\frac{w c_{1} b_{2}}{p_{B} D}\right) .
$$

so that

$$
\frac{\partial X_{d}^{D}(\mathrm{~N})}{\partial r(\mathrm{~N})}=\frac{\beta a_{1} b_{2}}{D}+\alpha\left(\frac{2 w b_{1}}{p_{B}}-\frac{c_{1} b_{2}}{D}\right) \frac{\partial\left(w / p_{B}\right)}{\partial r}
$$


In order to determine the sign of (26) we study the relationship between real wages and profits in the North:

$$
\frac{\partial\left(w / p_{B}\right)(N)}{\partial r(\mathrm{~N})}
$$

From equation (17) we obtain an expression relating changes in real wages to changes in the rates of profit across equilibria:

$$
\frac{\partial\left(w / p_{B}\right)(\mathrm{N})}{\partial r(\mathrm{~N})}=\frac{\beta a_{2}}{D \alpha\left(\frac{c_{2}}{D}-\frac{2 w}{p_{B}}\right)}
$$

This equation implies that the sign of $\partial\left(w / p_{B}\right) / \partial r$ is always the same as that of $\left(c_{2} / D\right)-\left(2 w / p_{B}\right)$. Substituting (27) into (26) and rearranging yields:

$$
\frac{\partial X_{v}^{D}(\mathrm{~N})}{\partial r(\mathrm{~N})}=\frac{\beta\left(\frac{2 w E}{p_{B}}+b_{2}\right)}{D\left(\frac{c_{2}}{D}-\frac{2 w}{p_{B}}\right)}
$$

which, in view of assumptions A.3 and C.2, must be positive. Therefore, the equilibrium rate of profit in the North increases with the volume of oil exported from the South. Note that (28) could also be positive even if $E<0$. The assumption $E>0$ is only used in this part of the proof, and thus it is not strictly necessary to obtain the required results.

We consider next the relation between the rate of profit in the North $r(\mathrm{~N})$ and the volume of its industrial exports. $\partial X_{I}^{S(\mathrm{~N})} / \partial r(\mathrm{~N})$. Note that since $v=0$ in the North, (19) implies $I^{D}=r K$. Since $X_{I}^{S(\mathrm{~N})}=I^{S}-I^{D}$, we have from (3), (4). (12) and (19):

$$
\frac{\partial X_{I}^{S(\mathrm{~N})}}{\partial r(\mathrm{~N})}=\beta\left(\frac{a_{1}}{D}-2 r\right)-\frac{\alpha \varepsilon_{1}}{D}\left(\frac{\partial\left(w / p_{B}\right)}{\partial r}\right)
$$

Since $a_{1} / D<2 r$ (condition 2) and since $\partial\left(w / p_{B}\right) / \partial r>0$, both terms on the right-hand side of (29) are negative: thus the rate of profit.r $(\mathrm{N})$ increases 
as exports from the North decrease, i.e.,

$$
\frac{\partial X_{I}^{S}(\mathrm{~N})}{\partial r(\mathrm{~N})}<0
$$

Since the supply of industrial goods $I^{S}$ is an increasing function of $r$, and by definition, $X_{I}^{S}=I^{S}-I^{D}$. it follows that as the rate of profit $r(\mathrm{~N})$ increases, the demand for industrial goods in the North must increase more than does its supply. This is due to income effects in the North: the demand for industrial goods increases significantly following a rise in the user's cost of capital. Therefore, exports of industrial goods decrease as the rate of profit $r(\mathrm{~N})$ increases.

Expressions (28) and (30) together imply that

$$
\frac{\partial X_{I}^{S}(\mathrm{~N})}{\partial X_{0}^{D}(\mathrm{~N})}=\frac{\partial X_{I}^{D}(\mathrm{~S})}{\partial X_{v}^{S}(\mathrm{~S})}<0 \text {, }
$$

i.e., the amounts of oil exported and industrial goods imported by the South move in opposite directions across equilibria.

Since $X_{d}^{S}(S)=p_{I} X_{I}^{D}(S)$, we have thus shown that

$$
\frac{\theta X_{v}^{S}(S)}{\partial p_{I}}>0
$$

i.e., a move towards a world equilibrium with increased oil exports from the South increases the relative price of industrial goods, i.e., worsens the terms of trade of the South. Furthermore, from (31), the volume of industrial goods imported by the South $X_{I}^{D}(\mathrm{~S})=X_{I}^{S}(\mathrm{~N})$ decreases as the volume of oil exported increases, so that the real revenues obtained by the oil exporter, in terms of industrial goods, have decreased as well. This completes the part of the proof concerned with international market effects. 
We turn now to the welfare implications of an increase in oil exports from the South on the domestic economies of the two regions. The proof will proceed by tracing the impact of the higher prices of industrial goods arising from the increase in oil exports. Under the stated assumptions, the rate of profit $\boldsymbol{r}(S)$ in the South increases with the price of industrial goods $p_{I}$. However, because of the dual nature of the southern economy (C.1), real wages, total employment and the domestic consumption of $B$ in the South all fall as $p_{I}$ and $r(S)$ rise.

We then consider the macro impacts on the North. Since the northern economy is relatively more homogeneous, an increase in the rate of profit in the North $r(\mathrm{~N})$ is associated with higher real wages, employment and domestic consumption of $B$ in the North. This will complete the proof of the theorem.

Our next task is thus to study the relationship between the international price of industrial goods $p_{I}$ and the rate of profit in the South $r(S)$.

Firstly, note that as the rate of profit $r(S)$ increases, the total capital $K$ available in the South increases, and therefore the supply of industrial goods, which are capital-intensive, also increases. Formally, since

$$
I^{S}=\left(a_{1} K-\varepsilon_{1} L\right) / D
$$

and $K=\beta T$, we have

$$
\begin{aligned}
\frac{\partial I^{S}}{\partial r} & =\frac{\beta a_{1}}{D}-\frac{c_{1}}{D}\left(\frac{\partial L}{\partial r}\right) \\
& =\frac{\beta a_{1}}{D}-\frac{\alpha c_{1}}{D}\left(\frac{\partial\left(w / p_{B}\right)}{\partial r}\right) .
\end{aligned}
$$

which is positive, since, from the dual nature of the economy (condition C.1) and (27), real wages and profits move in opposite directions in the South, $\partial\left(w / p_{B}\right) / \partial r<0$. 
As the supply of industrial goods $I^{S}$ increases with the rate of profit, the demand for oil must also increase in the South. This is because production of $B$ requires little oil $\left(b_{1}\right.$ is small) and oil demand is:

$$
\vartheta^{D}(S)=b_{2} I^{S}+b_{1} B^{S}
$$

Therefore,

$$
\frac{\partial v^{D}(S)}{\partial r} \sim b_{2}\left(\frac{\partial I^{S}}{\partial r}\right)>0
$$

Since $\vartheta^{S}=\vartheta^{D}+X_{\vartheta}^{S}$, and $p_{I} X_{I}^{D}=p_{\vartheta} X_{\Downarrow}^{S}$, we obtain (when $p_{\vartheta}=1$ ):

$$
\vartheta^{D}+p_{I}\left(\tau K-I^{S}\right)=0
$$

so that

$$
p_{I}=\frac{\vartheta D}{I^{S}-r K}
$$

We shall now check that the price of industrial goods increases with the rate of profit across equilibria.

As $2 r>a_{1} / D$ in the South by assumption, the expression

$$
\frac{\partial}{\partial r}\left(I^{S}-r K\right)=\beta\left(\frac{a_{1}}{D}-2 r\right)-\frac{\alpha c_{1}}{D}\left(\frac{\partial\left(w / p_{B}\right)}{\partial r}\right)
$$

is negative when $c_{1}$ is small.

Therefore, as $r(S)$ increases, the denominator of (36) decreases and the numerator increases. It follows that the equilibrium price of industrial goods increases with the rate of profit in the South, i.e.,

$$
\frac{\partial p_{I}}{\partial r(S)}>0
$$

which means that increases in oil exports are accompanied by increases in the rate of profit in the South. 
Now, from condition C.1 and (27), an increase in the rate $r(S)$ has the opposite effect on real wages: real wages in the South $w / p_{B}(S)$ decrease with increasing oil exports.

Together with equation (3), this implies that total employment must also decrease in the South; and since $B^{D}=w L / p_{B}$ (by 5) consumption of basic goods in the South must decrease as well.

Finally, we prove that increased exports of oil from the South have the opposite effect on the economy of the North. As imports of oil from the South $X_{\mathcal{V}}^{S}(\mathrm{~S})$ increase, the rate of profit in the North $r(\mathrm{~N})$ increases (by (2B)). The rate of profit $r(\mathrm{~N})$ now moves in the same direction as real wages (from C.2 and (27)). Therefore, real wages and the rate of profit both increase in the North with increases in oil imports. As real wages $w / p_{B}(N)$ increase, (3) shows that the total employment of labor $L(\mathrm{~N})$ will also increase, and the total consumption of basic goods in the North, $B^{D}=\alpha\left(w / p_{B}\right)^{2}$, must increase as well.

This completes the proof of the theorem.

In view of the negative impacts of increased oil exports on the economy of the South, it seems natural to consider whether an economy with these characteristics would export oil at all. One possible answer is that such an economy may export oil because the effects of increased oil exports are not uniformly bad across all income groups: both the rate of profit and the total profit income of the South increase with increases in oil exports, although the total real revenues of the region as a whole decrease. The following corollary focuses this result to demonstrate more clearly the role of the conditions of Theorem 1 on the welfare of different income groups. 
Corollary. Consider a move towards a new equilibrium characterized by increased oil exports from the South, and lower real export revenues. If the economy of the South has the characteristics assumed in Theorem 1, then both the rate of profit and the total profit income of the South will be higher at the new equilibrium, independent of the characteristics of the northern economy.

Proof. Consider a new equilibrium with increased oil exports, and lower real revenues for the South, $\partial X S(S) / \partial X P(S)<0$.

This implies that the relative price of industrial goods $p_{I}$ increases in the new equilibrium, i.e., the terms of trade of the South worsen. From (38) this implies that the rate of profit in the South $r(S)$ increases. Since by (4) $K=\beta r$, the total capital employed in the South also increases. Therefore since $r, p_{I}$ and $I$ all increase, the total profit income $r p_{I} K$ will necessarily increase as well, thus completing the proof of the corollary.

The next result explores the conditions under which increases in oil exports have positive effects on the welfare of the exporting region. This highlights the role of the structure of the economy in determining the welfare effects of oil export policies.

Theorem 2. Assume that the economies of the two regions are as assumed in Theorem 1, except that the condition $c_{2} / D<2 w / p_{B}$ for the South is replaced by $c_{2} / D>2 w / p_{B}$, i.e., there is more homogeneous use of capital and labor. Then an increase in oil exports will worsen the South's terms of trade and decrease its real revenues, but profits, real wages, employment and domestic consumption of basic goods will all increase at equilibrium.

Proof. An increase in the export of oil from the South $X_{j}^{S}$ will have a negative impact on the equilibrium volume of industrial goods imported $X_{I}^{D}$ and the South's terms of trade, since these depend only on the general equilibrium 
reaction of the North to increased oil exports from the South. (Recall that the northern economy is still exactly as assumed in Theorem 1.)

Increasing the amount of oil exported $X_{\vartheta}^{S}$ will again increase the rate of profit in the South, although not for the same reasons as in Theorem 1.

Consider expression (36):

$$
p_{I}=\frac{\vartheta^{D}}{I^{S}-r K}
$$

The denominator, $I^{S}-r K$, decreases with $r$ since

$$
\frac{\partial}{\partial r(S)}\left(I^{S}-r K\right)=\beta\left(\frac{a_{1}}{D}-2 r\right)-\frac{\alpha c_{1}}{D}\left(\frac{\partial\left(w / p_{B}\right)}{\partial r}\right)
$$

has a negative sign because $2 r>a_{1} / D$ and (27) implies that $\partial\left(w / p_{B}\right) / \partial r>0$. The numerator $\vartheta^{D}$ increases with $r$, since the expression

$$
\frac{\partial v^{D}}{\partial r(S)}=b_{2}\left(\frac{\partial I^{S}(S)}{\partial r(S)}\right)=\beta b_{2}\left(\frac{a_{1}}{D}-\frac{\alpha c_{1}}{D}\left(\frac{\partial\left(w / p_{B}\right)}{\partial r}\right)\right)
$$

is positive when $c_{1}$ is small. Therefore $p_{I}$ increases with the rate of profit $r(\mathrm{~S})$. The rate of profit $r(S)$, in turn, increases with oil exports, as seen above. Therefore, the price of industrial goods increases with oil exports:

$$
\frac{\partial X_{v}^{S}(S)}{\partial p_{I}}>0
$$

Finally, when the use of capital and labor is relatively homogeneous, so that $c_{2} / D>2 w / p_{B}$, we have $\partial\left(w / p_{B}\right) / \partial r>0$ (as noted above), so that real wages increase with the rate of profit in the South.

Thus, as oil exports increase, so do real wages. From (3) employment in the South also increases, and from (5) domestic consumption of $B$ grows as well. This completes the proof. 
Finally, we explore conditions under which the real revenues of the oil exporter can be expected to improve as the amount of oil exported increases. It will, of course, be necessary to assume that the oil importer has different characteristics to those put forward in Theorem 1.

Theorem 3. Assume that the oil importer has the characteristics described in Theorem 1 with two major exceptions:

1. Its economy is quite 'dualistic' in its use of capital and labor, i,e., $c_{2} / D<2 w / p_{B}$

2. Its basic goods sector uses relatively few capital inputs, i.e., $c_{1} \sim 0$.

Then an increase in oil exports will increase the real revenues of the oil exporter and improve its terms of trade. In the oil-importing country, the rate of profit and the domestic use of industrial goods will both decrease as a result of increased oil imports, but real wages, employment and consumption of basic goods will all increase.

Proof. Under the conditions of this theorem, we have (from equation 28)

$$
\frac{\partial X_{v}^{D}}{\partial r}=\frac{\beta\left[\frac{2 w E}{p_{B}}+b_{2}\right]}{D\left[\frac{c_{2}}{D}-\frac{2 w}{p_{B}}\right]}<0 \text {. }
$$

since $c_{Z^{\prime}} D<2 w / p_{B}$. Therefore as oil imports increase, the rate of profit decreases in the oil-importing country.

From equation (29), since $c_{1} \sim 0$ and $2 r>a_{1} D$, we obtain

$$
\frac{\partial X_{I}^{S}}{\partial r}=\beta\left(\frac{a_{1}}{D}-2 r\right)-\frac{\alpha c_{1}}{D}\left(\frac{\partial\left(w / p_{B}\right)}{\partial r}\right)<0 \text {. }
$$

which implies that industrial exports now increase as oil imports increase: the real revenues of the oil importer now improve with increased oil exports. 
Since $\left(c_{2} / D\right)-\left(2 w / p_{B}\right)$ is now negative for the oil-importing country, $\partial\left(w / p_{B}\right) / \partial r<0$ from (27), i.e., a lower profit rate is associated with higher real wages, employment and domestic consumption of basic goods (see also (3) and (5)).

Equation (33) and $\partial\left(w / p_{B}\right) / \partial r<0$ imply that the domestic supply of industrial goods $I^{S}$ now decreases since the rate of profit $r$ decreases as oil imports increase. Since the domestic use of industrial goods $I^{D}$ equals $I^{S}-X_{I}^{S}$, and exports $X_{I}^{S}$ are increasing while output $I^{S}$ is decreasing, the volume of industrial goods used domestically $I^{D}$ must therefore be lower. This completes the proof.

\section{DISCUSSION AND CONCLUSIONS}

The results suggest that certain macro characteristics of the trading economies will have a significant effect on the outcomes of resource export policies. This section summarises our findings and suggests ways in which they may be useful in policy analysis.

We studied the conditions under which increasing the export of resources has either positive or negative consequences for the exporting economy. These conditions concern the internal characteristics of the trading economies: when the exporter uses capital and labor with different intensities in different sectors of the economy, and the importer employs these factors more homogeneously, increasing resource exports may lead to worse terms of trade for the exporter, lower real wages and employment levels, but higher profits (Theorem 1). When the exporter has a more homogeneous economy, the results are partly, or fully, reversed (Theorems 2 and 3 ).

It is interesting that one of the crucial conditions on which the results of resource trade depend is the same condition that explains gains or losses from 
trade in basic goods in a previous paper (Chichilnisky, 1981). This is a measure of the homogeneity of the economy, expressed by $\left(c_{2} / D\right)-\left(2 u / p_{B}\right)<0$. where $D$ represents the level of "duality" in the economy and $w / p_{B}$ is the real wage. When the importer has a more homogeneous economy than the exporter $\left(\left(c_{2} / D\right)-\left(2 w / p_{B}\right)>0\right)$ and the rates of profit are high $\left(a_{1} / D<2 r\right)$. then the relation between oil exports and their price slopes downward across equilibria, as was the case for the export of basic consumption goods in Chichilnisky (1981). It therefore seems worth discussing the role of the expression $\left(c_{2} / D\right)-\left(2 w / p_{B}\right)$ further.

The sign of the expression $\left(c_{2} / D\right)-\left(2 w / p_{B}\right)$ determines whether the profit rate and real wages vary directly or inversely across equilibria. The extent to which the rewards to capital and labor move together, or in opposite directions, therefore seems to depend on the homogeneity of the economy. It seems that, in more homogeneous economies, increases in the rate of profit have a positive external effect on real wages, while in 'dual' economies, they compete, one increasing only when the other decreases.

It may be useful to explain briefly what 'drives' the results, starting with the impact of increased resource exports on the international economy and on the resource-importing region.

We saw in Theorem 1 that a higher volume of resources is traded for a lower volume of industrial goods, so that the relative price of industrial goods increases at the new world equilibrium. What drives this result is a negative correlation between the price of industrial goods and the volume of industrial goods exported. This negative correlation is similar to that demonstrated in Chichilnisky (1981) between the volume of labor-intensive basic goods exported from a developing country and their price. In both cases, the negative correlation is due to general equilibrium income effects, effects that can 
be observed only as we allow supply and demand curves to shift simultaneously. As the price of industrial goods rises, the domestic supply increases, but the domestic demand increases more, thus lowering the surplus available for export. Higher oil exports are associated with higher profits and higher industrial prices; therefore increases in oil exports are associated with a decrease in industrial exports. The terms of trade of the industrial exporter necessarily improve.

This improvement in terms of trade benefits the industrial economy: since this type of economy is quite homogeneous and integrated, an increased supply of industrial goods leads to higher levels of overall employment, real wages, and consumption of both goods. The impacts of increased resource imports are thus unambiguously positive for an industrial exporter.

These results are reversed when the resource-importing economy is less homogeneous, has a "dual" economic structure, and uses less capital and resources to produce its basic consumption good. (These features are perhaps more characteristic of a developing resource-importing economy.) The impacts of an increase in resource imports are then less positive. This is demonstrated in Theorem 3 by tracing the general equilibrium effects corresponding to those observed in Theorem 1. Following an increase in resource imports, the importing country uses less industrial goods and its rate of profit is smaller. However, the equilibrium values of real wages, employment and consumption of basic goods are all higher. Increasing the amount of resources imported seems to lead to an economy more oriented to basic consumption and production, a form of 'de-industrialization'. 
So far we have examined the impacts of increasing resource exports on the resource-importing country and on the international economy. We shall now discuss the impact of these international market changes on the resource exporter.

As with the above results, different degrees of heterogeneity and lack of integration lead to rather different results. In Theorem 1, the resourceexporting region has a dual economy, uses few capital and resource inputs in its basic consumption sector, and initially has a relatively high profit rate. In this case, increases in resource export volumes increase profits and total profit income, but the terms of trade and the export revenues of the region both fall:

Due to the heterogeneity and lack of integration of this economy, increased profits lead not to higher, but rather to lower levels of employment, real wages and wage income, as well as to decreased output and consumption of basic goods. In order to regain its previous level of consumption of industrial goods, the region must now increase its industrial output, since imports have decreased. The only gain from increased resource exports is an increase in profit income. These results are traced, in Theorem 1 as well as in Chichilnisky (1981), to general equilibrium income effects, which are very sensitive to the degree of dualism of the economy. These results appear more sharply in the Corollary, which considers only the characteristics of the exporting economy.

The overall conclusion is that an integrated and homogeneous economy may benefit unambiguously from increased imports of resources from a region which has a dual economy. For the resource exporter to benefit from increased exports it seems to be necessary to trade with similar economies, or else to keep its economy as integrated and homogeneous as possible. The 
results are therefore very similar to those given in Chichilnisky (1981), although they apply to rather different sets of circumstances, as discussed above.

In 'dual' economies, the proceeds from resource exports go mainly to a small, internationally linked, industrial sector. Under these conditions, reliance on resource exports may worsen the international position of the economy in the long run if the region trades with a more homogeneous industrial economy. Resource exports may translate into higher profit income, but this does not necessarily 'circulate' through the economy; it may raise the price of imported industrial goods, without bringing about improvements in welfare (employment, real wages, etc.).

It should be noted that the characteristics which determine whether expansion of oil exports is desirable or not also determine the optimal balance of goods between domestic and foreign markets. This can be seen as follows. The characteristics concerned are the structure of the economy (which is exogenous) and the endogenous factor prices. Since the equilibria of the economy are calculated for given export volumes, it follows that whether the effect of increasing resource exports is beneficial or not will depend on the initial export level and the structure of the domestic economy. The equilibrium level of exports also affects the desirability of expanding oil exports. Thus, it is possible to use these results to obtain an optimal level of exports for a given economy, i.e., one that balances the export sector with the other sectors of the domestic economy.

A number of extensions and improvements of this model seem desirable. In particular, some of the dynamic aspects of the problem may be usefully developed in the context of optimal depletion rates $\approx$ la Hotelling. 


\section{APPENDIX}

In this appendix explicit solutions to the model are found. It is shown, in particular, that the set of equilibria describes a one-parameter family, characterized by the volume of resources exported.

Oil will be taken as the numeraire in the following analysis, i.e., $p_{v}=1$.

We shall first explore the relationships between factor markets and the domestic market for basic consumption goods in each region. The links between these domestic markets and the international markets for oil and industrial goods will then be examined.

Consider now the equilibrium relation $B^{D}-B^{S}=0$. At equilibrium we have, from (3) and (5),

$$
B^{D}=\alpha\left(\frac{w}{p_{B}}\right)^{2}
$$

and from (3), (4) and (11)

$$
B^{S}=\left(c_{2} L-a_{2} K\right) / D=\left(\frac{\alpha c 2^{w}}{p_{B}}-\beta a_{2} r\right) / D
$$


i.e.,

$$
B^{S}-B^{D}=\left(\left(\frac{\alpha c{ }^{w}}{p_{B}}-\beta a_{2} r\right) / D\right)-\alpha\left(\frac{w}{p_{B}}\right)^{2}=0
$$

This is a quadratic expression in $w / p_{B}$, whose roots are

$$
w / p_{B}=\frac{c_{2}}{2 D} \pm\left[\frac{c_{2}^{2}}{4}-\frac{\beta a_{2} r}{\alpha D}\right]^{1 / 2}
$$

Thus (A.4) gives two equilibrium values of real wages for each given rate of profit, as well as an upper bound for $r$, in each region:

$$
r<\frac{c_{2}^{2} \alpha D}{4 \beta a_{2}}
$$

Note that the smaller root of $w / p_{B}$ in (A.4) is an increasing function of $r$, and the larger a decreasing function of $r$.

Consider the amount of industrial goods imported by the South, $X_{I}^{D}(S)$. Across the equilibria we have, by definition,

$$
X_{I}^{D}=I^{D}-I^{S}
$$

From the national income identity (18) and the demand condition (5), we obtain the following equation for the amount of industrial goods imported at equilibrium:

$$
X P(S)=\tau K+\frac{p_{\vartheta} \vartheta}{p_{I}}-I^{S}(S)
$$

Now, $p_{I} X_{I}^{D}(S)=p_{\vartheta} X_{q}^{S}(S)$ across equilibria because of the balance of payments condition. Since $\vartheta=\vartheta^{D}+X^{S}$, we have

$$
r K+\frac{p_{\vartheta} \vartheta D}{p_{I}}-I^{S}=0
$$


when the southern economy is in equilibrium. Substituting the equations for the supply of labor (3), capital (4) and industrial goods (12) into (A.8) yields the following implicit relation between the international equilibrium price of industrial goods, $p_{I}$, and the domestic factor prices (rate of profit and real wages) in the South:

$$
\beta r\left(r+\frac{a_{1}}{D}\left(\frac{b_{2} p_{v}}{p_{I}}-1\right)-\frac{a_{2} p_{v} b_{1}}{p_{I} D}\right)+\frac{\alpha w}{D p_{B}}\left(\frac{c_{2} b_{1} p_{v}}{p_{I}}+c_{1}\left(1-\frac{b_{2}}{p_{I}}\right)\right)=0
$$

We saw in (A.4) that $w / p_{B}$ is a (two-branched) function of $r$, and so substituting (A.4) into (A.9) leads to an expression linking the rate of profit in the South $r(S)$ and the international price of industrial goods, $p_{I}$, across equilibria.

We shall now turn to the North. Consider the amount of industrial goods exported $X_{I}^{S}(\mathrm{~N})$. Recalling that the North does not produce oil, we obtain the equilibrium relation

$$
\begin{aligned}
X_{I}^{S}(\mathrm{~N})=I^{S}-I^{D} & =\left(\left(a_{1} K-c_{1} L\right) / D\right)-r K \\
& =\beta\left(\frac{a_{1} r}{D}-r^{2}\right)-\frac{\alpha c_{1} w}{D p_{B}} .
\end{aligned}
$$

where the parameters and variables now refer to the North.

We shall show that for each given value of oil exports from the South $X_{\mho}^{S}(S)$, the North-South general equilibrium model is 'closed', and a solution can be given analytically.

Since $X_{\mho}^{S}(\mathrm{~S})=X_{\vartheta}^{D}(\mathrm{~N})$ at equilibrium, (3), (4) and (5) can be used to obtain an expression relating the amount of oil exported from the South and the factor prices in the North:

$$
X_{\mathfrak{v}}^{S}(S)=\frac{\beta a_{1} b_{2} r}{D}+\alpha\left(b_{1}\left(\frac{w}{p_{B}}\right)^{2}-\frac{c_{1} b_{2}{ }^{w}}{D p_{B}}\right)
$$


(the variables and parameters on the right-hand side are for the North). Thus (A.11) gives an implicit relation between two factor prices in the North, $r(N)$ and $w / p_{B}(\mathrm{~N})$ for each level of oil exports.

Using this equation together with (A.4), which gives another (independent) implicit relation between these factor prices, we can then obtain the equilibrium values $r(\mathrm{~N}) *$ and $w / p_{B}(\mathrm{~N}) *$ corresponding to each given oil export volume $X_{d}^{S}(S)$.

From equations (3) and (4) it is then possible to calculate the equilibrium utilization of labor and capital in the North, $L(\mathrm{~N}) *$ and $K(\mathrm{~N}) *$. Equations (11) and (12) can then be used to compute the output of consumption good $B$ and industrial good $I$ at equilibrium, $B(\mathrm{~N}) *$ and $I(\mathrm{~N}) *$. From (A.10) we determine the amount of industrial goods exported $X_{I}^{S}(\mathrm{~N}) *$. We then determine the demand for oil in the North, $\vartheta^{D}(\mathrm{~N}) *$, from equation (15), and using the balance of payments condition, $v^{D}(\mathrm{~N}) *=X_{v}^{S}(\mathrm{~S}) *=p_{I} X_{I}^{S}(\mathrm{~N}) *$, we obtain the international equilibrium price of industrial goods $p_{i}$.

Finally, we consider the following two price equations (for the North), which may be derived directly from the production relations (1) and (2) under the assumption that factors are used competitively:

$$
\begin{gathered}
p_{B}=a_{1} w+b_{1} p_{0}+c_{1} r p_{I} \\
p_{I}=a_{2} w+b_{2} p_{0}+c_{2} r p_{I}
\end{gathered}
$$

Recalling that oil is assumed to be the numeraire, and since both $p_{I}(\mathrm{~N}) *$ and $r(\mathrm{~N}) *$ are elready known, we can obtain the nominal wage $w(\mathrm{~N}) *$ from (A.13). We can then calculate the equilibrium price of $B, p_{B}(N) *$ from (A.12). This completes an equilibrium solution for the North, for any given volume of oil exports from the South $X_{q}^{S}(\mathrm{~S})$. 
We shall now compute the equilibrium for the South, noting that for each given $X_{\vartheta}^{S}(\mathrm{~S})$ we have already determined both the level of industrial imports to the South (since $X_{I}^{D}(\mathrm{~S}) *=X_{I}^{S}(\mathrm{~N}) *$ at equilibrium) and the international equilibrium price of these imports $p_{I}$. Equations (A.4) and (A.11) therefore give two (independent) relations between real wages and the rate of profit in the South, which allows us to compute the equilibrium values $w / p_{B}(S) *$ and $r(S) *$. From equations (A.12) and (A.13) we then obtain $p_{B}(S) *$ and $w(S) * ;$ from (3) and (4), $K(\mathrm{~S}) *$ and $L(\mathrm{~S}) *$; from (11) and (12), $I^{S}(\mathrm{~S})^{*}$ and $B^{S}(\mathrm{~S}) *$ and from (15), $\vartheta(\mathrm{S}) *$. This completes a general equilibrium solution of the North-South model. Note that for each level of oil exports $X^{S}(S)$ there will generally exist more than one solution, depending on the initial parameter values and the characteristics of both economies. However, there should be only a finite number of these solutions, i.e., they are locally unique. Thus, as the scalar $X_{v}^{S}(S)$ varies, we obtain a (local) one-parameter family of equilibria. Note also that a level of oil supplies below the feasible bound $\vartheta$ may be obtained for some equilibria. This can happen as follows. For each level of oil exports from the South $X_{0}^{S}(S)$. we obtain the level of imports of industrial goods $X P(S)$ * and their equilibrium price $p_{i}$ from the equilibria of the North (computed as above). Given these two variables, the domestic supply of basic and industrial goods in the South. $B^{S^{*}}$ and $I^{S^{*}}$, is determined, which allows us to calculate the domestic demand for oil in the South, $v^{D}=b_{1} B^{S}+b_{2} I^{S}$. The feasibility condition requires that $X_{v}^{S}(S)+v^{D}(S) \leq \vartheta$, but the above computation of total oil used does not imply that all the oil available is actually utilized, i.e., $X_{v}^{S}(\mathrm{~S})+\vartheta^{D}(\mathrm{~S})<\bar{\vartheta}$ is in principle possible. However, it is interesting to note that even though there may be "excess supply" of oil at equilibrium, the relative price of oil need not be zero because the relative price of oil is determined by the international market equilibrium condition 


$$
\frac{p_{\vartheta}}{p_{I}}=\frac{X Y(\mathrm{~N})}{X_{v}^{D}(\mathrm{~N})}
$$

i.e., the model assumes a "passive" determination of relative oil prices by real international markets. 


\section{REFERENCES}

Benavie, A (1978) "Foreign Prices and Income in a Macromodel with Two Domestic Sectors". International Economic Review.

Bliss, C. (1981) "Macro-economics of Open Economies". Paper delivered at the Association of University Teachers of Economics, Loughborough.

Chichilnisky, G. (1981) "Terms of Trade and Domestic Distribution: Export-Led Growth with Abundant Labour". Joumal of Development Economics, Vol. B, pp. 163-192.

Chichilnisky, G. (1983) "Oil Prices, Industrial Prices and Output: A General Equilibrium Macro Analysis". Working Paper, International Institute for Applied Systems Analysis, Laxenburg, Austria (forthcoming).

Corden, W.M. (1982) "Booming Sector and Dutch Disease Economics: A Survey". Working paper No. 079, The Australian National University.

Cremer, J. and D. Salehi (1980) "A Theory of Competitive Pricing in the Oil Market: What Does OPEC Really Do?" CARESS Working Paper No. 80-4, University of Pennsylvania, 1980.

Dasgupta, P.S., and G.M. Heal (1979) Economic Theory and Exhaustible Resources. Nisbet/Cambridge University Press. 